Boston University School of Law Scholarly Commons at Boston University School of Law

Faculty Scholarship

2011

\title{
Poverty Tourism and the Problem of Consent
}

Kevin Outterson

Boston Univeristy School of Law

Follow this and additional works at: https://scholarship.law.bu.edu/faculty_scholarship

Part of the Law Commons

\section{Recommended Citation}

Kevin Outterson, Poverty Tourism and the Problem of Consent, 7 Journal of Global Ethics 337 (2011).

Available at: https://scholarship.law.bu.edu/faculty_scholarship/520

This Article is brought to you for free and open access by Scholarly Commons at Boston University School of Law. It has been accepted for inclusion in Faculty Scholarship by an authorized administrator of Scholarly Commons at Boston University School of Law. For more information, please contact lawlessa@bu.edu. 
This article was downloaded by: [Michigan State University], [Kyle Powys Whyte] On: 16 December 2011, At: 11:05

Publisher: Routledge

Informa Ltd Registered in England and Wales Registered Number: 1072954 Registered

office: Mortimer House, 37-41 Mortimer Street, London W1T 3J H, UK

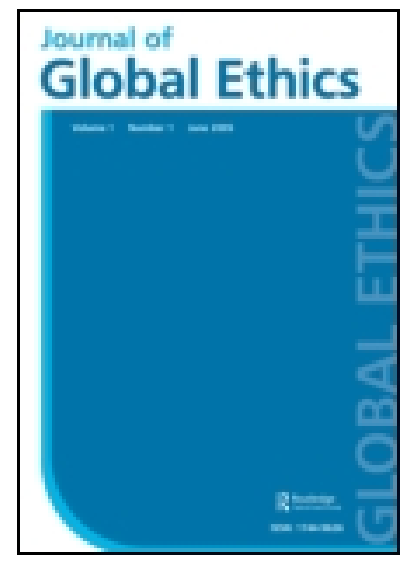

\section{J ournal of Global Ethics}

Publication details, including instructions for authors and subscription information:

http:// www.tandfonline.com/loi/ rjge20

\section{Poverty tourism and the problem of consent}

Kyle Powys Whyte ${ }^{a}$, Evan Selinger ${ }^{b} \&$ Kevin Outterson ${ }^{c}$

a Department of Philosophy, Michigan State University, 503 S. Kedzie Hall, East Lansing, MI, 48824, USA

${ }^{b}$ Department of Philosophy, Rochester Institute of Technology, Rochester, NY, USA

c Boston University School of Law, Boston, MA, USA

Available online: 16 Dec 2011

To cite this article: Kyle Powys Whyte, Evan Selinger \& Kevin Outterson (2011): Poverty tourism and the problem of consent, J ournal of Global Ethics, 7:3, 337-348

To link to this article: http:// dx.doi.org/ 10.1080/ 17449626.2011.635689

\section{PLEASE SCROLL DOWN FOR ARTICLE}

Full terms and conditions of use: http://www.tandfonline.com/page/terms-andconditions

This article may be used for research, teaching, and private study purposes. Any substantial or systematic reproduction, redistribution, reselling, loan, sub-licensing, systematic supply, or distribution in any form to anyone is expressly forbidden.

The publisher does not give any warranty express or implied or make any representation that the contents will be complete or accurate or up to date. The accuracy of any instructions, formulae, and drug doses should be independently verified with primary sources. The publisher shall not be liable for any loss, actions, claims, proceedings, demand, or costs or damages whatsoever or howsoever caused arising directly or indirectly in connection with or arising out of the use of this material. 


\title{
Poverty tourism and the problem of consent
}

\author{
Kyle Powys Whyte ${ }^{\mathrm{a} *}$, Evan Selinger ${ }^{\mathrm{b}}$ and Kevin Outterson ${ }^{\mathrm{c}}$ \\ ${ }^{a}$ Department of Philosophy, Michigan State University, 503 S. Kedzie Hall, East Lansing, MI 48824, USA \\ ${ }^{b}$ Department of Philosophy, Rochester Institute of Technology, Rochester, NY, USA; ${ }^{c}$ Boston University \\ School of Law, Boston, MA, USA
}

\begin{abstract}
Is it morally permissible for financially privileged tourists to visit places for the purpose of experiencing where poor people live, work, and play? Tourism associated with this question is commonly referred to as 'poverty tourism'. While some poverty tourism is plausibly ethical, other practices will be more controversial. The purpose of this essay is to address mutually beneficial cases of poverty tourism and advance the following positions. First, even mutually beneficial transactions between tourists and residents in poverty tourism always run a risk of being exploitative. Second, there is little opportunity to determine whether a given tour is exploitative since tourists lack good access to the residents' perspectives. Third, if a case of poverty tourism is exploitative, it is so in an indulgent way; tourists are not compelled to exploit the residents. In light of these considerations, we conclude that would-be tourists should participate in poverty tours only if there is a well-established collaborative and consensual process in place, akin to a 'fair trade' process.
\end{abstract}

Keywords: tourism ethics; exploitation; alternative tourism; reality tourism; fair trade

\section{Introduction}

Is it morally permissible for financially privileged tourists to visit places for the purpose of experiencing where poor people live, work, and play? Tourism associated with this question is commonly referred to as 'poverty tourism' (or, more pejoratively, as 'poorism') (Lancaster 2007, 37; Rolfes 2010). While some poverty tourism is plausibly ethical (Selinger and Outterson 2010), other practices will be more controversial. This paper considers three criteria that typify controversial cases of poverty tourism. First, their explicit purpose is to provide tourists with a personal observation of poverty. Second, tourists select a particular tour because they believe it will provide authentic (but safe) experiences. Third - and most controversially - when planning the tour, meaningful collaboration between residents and tourists does not occur, denying residents the opportunity to consent or object. ${ }^{1}$ We find the lack of consent to be initially troubling and explore it further in this paper.

Poverty tourists are drawn to a variety of places, from squatter settlements in India to garbage dumps in Mexico and to urban centers in the USA. Some philosophers, journalists, and writers condemn all such tours as harmful cases of voyeurism. Others disagree, insisting that some tours are not harmful at all, and actually generate important human interactions, including education and economic assistance. These mutually beneficial cases are invoked as counterexamples that deflate critics' claims that all cases of poverty tourism are impermissible. The counterexamples also include 'Pareto superior' cases where the tourists gain but the residents are made no worse off.

\footnotetext{
*Corresponding author. Email: kwhyte@msu.edu
} 
The purpose of this essay is to address these cases and advance the following positions. First, even mutually beneficial transactions between tourists and residents in poverty tourism always run a risk of being exploitative. Crucially, tourists might take advantage of the residents' poverty through transactions that leave the residents with less compensation or less privacy than they deserve (that is, the outcomes are Pareto superior but not Pareto optimal). Second, and owing to the third criterion above, there is little opportunity to determine whether a given tour is exploitative since tourists lack good access to the residents' perspectives. Third, if a case of poverty tourism is exploitative, it is so in an indulgent way; tourists are not compelled to exploit the residents. In light of these considerations, we conclude that would-be tourists should participate in poverty tours only if there is a well-established collaborative and consensual process in place.

\section{Defining poverty tourism}

Throughout the world, many cases of poverty tourism can be found. Salient examples include tours of slums in India and Brazil and trips to garbage dumps to serve meals while scavengers sort through newly deposited trash. Sometimes poverty tourists simply take their own initiative and walk through a neighborhood or region, while other walkers seek to chat with locals, taste the typical food, and make small purchases. Recent articles in Newsweek, New York Times, Smithsonian, The Wall Street Journal, and The Huffington Post have described some of the more concrete details (Kohn 2008; Lancaster 2007; Moroney 2007; Weiner 2008). The Guardian reports Dutch tourists come 'well prepared for the walking safari' with 'strong shoes and sunscreen, backpacks and bottled water'. These tourists are off to see a slum named Kiberia where, for twenty pounds, they

... are promised a glimpse into the lives of the hundreds of thousands of people crammed into tiny rooms along dirt paths littered with excrement-filled plastic bags known as "flying toilets," as one tour agency explains on its website. (Rice 2009, http://www.guardian.co.uk/world/2009/sep/25/ slum-tourism-kenya-kibera-poverty)

Other poverty tourism trips, such as homestays, are more long term. An example of this type of tour is Beyond Border's 'Transformational Travel' program. Its promotional material states that, 'Participants travel to Haiti, stay in the homes of poor Haitians, and learn more of their struggle to organize and build a better life for themselves. They interact, through translators, learning about their faith, their struggles and joys'. ${ }^{2}$

The cases just discussed trace their roots to the mid-1980s when companies like Favela Tour and Face to Face Tours began offering walking tours of slums in Rio de Janeiro and Soweto in South Africa. Some 20 years later, the founder of Face to Face claims to have guided more than a million people through Soweto (Baran 2008; Ramchander 2007). ${ }^{3}$ Poverty tourism also exists in wealthy countries and is often associated with particular themes that some people associate (problematically and prejudicially) with poverty, such as gang tours in Los Angeles, California and gospel choir tours of Harlem, New York (Archibold 2010). Although poverty tours usually do not offer direct compensation to the residents, operators often encourage tourists to donate to a charitable organization working in the region. Some poverty tours are conducted by these charitable organizations (including Transformational Travel), and the proceeds fund their activities directly. Other times, tourists stroll through a particular area without compensating anybody beyond some small purchases from vendors in the area.

Poverty tourism is controversial because poverty tourists might be using their privilege to indulge their curiosity about other people's misfortunes. Although many kinds of tourism provide tourists with personal observations of poverty, our attention will be restricted to cases that meet the three criteria that we touched on at the beginning of the paper: 
(1) The driving purpose is for tourists to observe poverty personally. This purpose may or may not be accompanied by a desired outcome, such as 'to help alleviate poverty', 'to provide education', 'to be informed', and so on. ${ }^{4}$

(2) Tourists believe that the activities will provide an authentic experience of poverty. Since the tourists are neither poor nor from the local area, the conditions that they perceive in advance as vouching for such authenticity are based on prior assumptions about what poverty is like. Insofar as these prior assumptions influence the decision to go on a tour, we will refer to them as 'authenticity assurances'.

(3) Planning specific activities does not involve meaningful collaboration and consent between residents and tourists. 'Meaningful collaboration' here refers to any collaborative or participatory process through which the residents' perspectives and voices shape the way in which the tourism activities are envisioned and carried out. 'Consent' requires, at a minimum, adequate information and a realistic opportunity to have one's objections taken seriously. ${ }^{5}$ Meaningful collaboration is absent when one of the following three scenarios occurs. Sometimes tourists negotiate with a tourism operator who, in turn, negotiates with representatives of the residents. ${ }^{6}$ In this case, collaboration is limited, as it occurs indirectly through mediation, with the tour guide occupying a position of cultural authority. In other instances, the tourism operator holds cultural authority without negotiation. In this case the would-be tourist does not exercise any effort to understand what conditions the residents consider to be fair or appropriate. In the third instance, the tourist does not use the services of a tourism operator at all. While post hoc collaboration can occur in meaningful ways, this approach relies on good fortune rather than the application of methods for ensuring, prospectively, that the tour will be organized around interactions that residents find acceptable. To give residents greater autonomy, the collaboration process should include the opportunity for the residents to either consent or veto the tours.

We selected criteria (1)-(3) in order to focus on more controversial tours. In articles about poverty tourism, we have seen few if any that provide scandalous accounts where tourists and operators engaged the residents in a collaborative and consensual process or where the tourists did not have certain preconceived assumptions about what authentic poverty was like or where the explicit purpose was something other than experiencing poverty. Long-term residence by Peace Corp volunteers, anthropologists conducting research, or mission hospital doctors are examples where other purposes predominate. Tours that do not meet any one of the three conditions may simply not be poverty tourism, and should be referred to as 'pro-poor', 'coalition-based', or 'justice' tourism or perhaps not tourism at all. In other cases, especially when criterion (1) is met but not criteria (2) and (3), the tour may be best referred to as poverty tourism of a coalition or community-based kind; some 'reality' and 'volunteer' tours take this form (see note 1).

\section{The debate over the morality of poverty tourism}

The debate over the morality of poverty tourism has historically not progressed beyond the following form of argumentative exchange: Critics of poverty tourism claim that it is voyeurism and associate it with widely repudiated harms; 'qualified acceptors' concede that such harms do occur in many tours, but cite counterexamples where the purpose is tied to educational benefits, and the tourists, operators, and residents are all better off (or at least the residents are not made any worse off) as a result of the trip. Qualified acceptors often conclude that these tours are permissible and, in some cases, may be aptly characterized as economic development activities. Let us explore some paradigmatic claims in greater detail. 
Some people claim that poverty tourism is voyeurism aimed at extremely vulnerable populations. Ian Stalker states that poverty tourism 'specifically showcase[s] squalid Third World neighborhoods to foreign tourists' (Stalker 2008). Stalker's use of 'showcase' indicates that tourists seek to be entertained by others' most unfortunate of circumstances, often without their consent. When applicable, this is a powerful criticism. It is hard to make the case for the permissibility of entertainment that comes at the expense of peoples' misfortunes, especially when it is accompanied by degradation, disrespect, and perpetuation of social subordination, i.e. harms covered in the debates about voyeurism involved in pornography (Dworkin 1981; Langton 1990, 1993; Mackinnon 1987, 1992). The analogy to pornography is especially apt, as its critics often express concern about related harms to women, such as prostitution. In the case of poverty tourism, the trafficking of women to some tourists can be an issue, at least in one Brazilian favela we are aware of.

Poverty tourism may also commodify the residents (Freire-Medeiros 2009). David Fennell writes,

Maybe you give 1 or 2 or 3 or 4 percent of the profit back to the community, but you've now commodified these people, you've turned them into a product in the service of an industry. I'm not sure that's ethical... We feel we have the right to go anywhere we want on the planet... Everest. Antarctica. The Amazon. Wherever. If you put your money down, you have a right to go. ${ }^{7}$

This argument flows from a large literature critical of commodification and consumption in tourism (Coleman and Crang 2002; Johnston 2006; Kirshenblatt-Gimblett 1998; Rojek and Urry 1997; Smith 1989; Sturken 2007).

Others contend that poverty tourism is wrong because the residents are subject to invasions of privacy, demeaning treatment, dishonesty, misrepresentation, and impropriety. These views are documented by Selinger (2009) and Selinger and Outterson (2010), and call attention to harms that are generally considered wrong in most other contexts (Selinger 2009; Selinger and Outterson 2010).

Qualified acceptors tend to concede that some cases of poverty tourism inflict harm. Nevertheless, they maintain that poverty tourism is not an inherently harmful practice. Steven Gillick, President of the Canadian Institute of Travel Counselors, argues that a case of poverty tourism would be permissible if the tourists' '... motives are geared toward the spirit of both education and assistance'. He further claims that

[I]f these two criteria can be met, then what some cynically refer to as poor-ism becomes, in effect, responsible tourism - seeing, learning, understanding, appreciating, helping and taking pride in doing something tangible to help make our world a better place. (Stalker 2008, 21).

According to Gillick, then, poverty tourism is permissible if the first hand viewing of poverty engenders important benefits like education and economic assistance.

Selinger and Outterson agree that some forms of poverty tourism may not be harmful. They open one of their essays with the following caveat,

We do not defend all or even most poverty tourism practices ... empirical work may find that most poverty tours are ethically objectionable as voyeuristic experiences ... Our delimited task has been ... to resist categorical condemnation of poverty tours. (Selinger and Outterson 2010, 112).

Their point is that while cases of poverty tourism featuring explicit harms are impermissible, counterexamples show that poverty tourism itself cannot be condemned $a$ priori. Referring to Outterson's experiences, they critically discuss a poverty field trip taken by graduate students at West Virginia University to a slum in Rio de Janeiro, Brazil. After exploring the context, they note, 'The West Virginia program is primarily educational, and therefore may not be representative of poverty tourism in general'. 
In a similar aspirational tone, Nilima Achwal writes, 'It's easy to go on debating whether these tours are right or wrong, but it may be more practical to delineate aspects that make the tours more sensitive to and empowering for local communities'. She articulates six different ways that poverty tours can be more sensitive and empowering: (1) local residents are employed, (2) the majority of profits accrue to the community, (3) good behavior is reinforced and bad behavior sanctioned, (4) the local economy is supported, (5) the tourist agency fosters the tourists' open-mindedness, and (6) new infrastructure should be built for the residents, not to accommodate the tourists (Achwal 2010). With these norms in mind, she concludes that although there are inevitable problems associated with poverty tourism, it remains possible to advocate for tours that benefit the residents:

Are cautious, well-executed tours to poor areas ideologically harmful for the tourists and the locals? Perhaps. We can argue that they will only reinforce beliefs of the privilege and superiority of Westerners, for both parties. But what doesn't? In fact the only thing that doesn't continually reinforce the unequal dynamic resulting from colonialism is genuine person-to-person interactions, when one can't help but feel on the same level. Whether these tours can achieve that remains to be seen; we must hope that the majority of tourists will leave the villages and slums feeling inspired, and that business successes will empower locals, leaving them both materially and ideologically better off.

In sum, the counterexamples expressed by Gillick, Selinger, Outterson, and Achwal all point to tours that satisfy Pareto superior conditions: where provisions of education, assistance, and oversight ensure that no one is made worse off, and where at least some or all of the tourists, operators, and residents are made better off. Yet we do not feel that this is all there is to say about the morality of poverty tourism; in the next section, we explore additional concerns through more detailed analyses of some examples of potentially Pareto superior cases.

\section{Examples of poverty tourism for analysis}

Our analysis of mutually beneficial and Pareto superior cases begins with three examples that meet criteria (1)-(3) described in Section 2. ${ }^{8}$

(I) Poverty Tourism Homestays. A group of tourists from country A contracts with an operator in country B. The latter provides a guide that chaperones the group on a trip to a rural village or urban community where each tourist stays with a resident. Tourists pay a price that covers their travel expenses, the operator's fees, homestay costs to the residents (e.g. food, supplies, and profit), and a donation to a charitable organization. The operator sets the homestay profit to be low enough that the residents would not be motivated to behave much differently than they do in their everyday lives. This pricing scheme supposedly ensures that the tourists actually see what it is like to live in that community, which, after all, is a primary selling point. Indeed, the tour is advertised as a 'transformational experience' because the tourists are promised personal observations of the real living conditions in the community.

(II) Poverty Tourism Side Trips. While attending a professional conference in area B, some business people traveling from area A decide to take a day off, get a taxi to a well-known, lowerincome neighborhood, and spend the day wandering around the vicinity. They tell their colleagues that they would not want to have visited B without experiencing the poverty characteristic of the 'real B'. One of the tourists says that she wants to ask the locals some questions about their lives as well as sample some of the street food. Another says that he does not want to interact this way because it might disrupt what the people in the neighborhood are doing, thus spoiling the experience. The tourists end up spending the day strolling through the neighborhood and commenting among themselves about what they are experiencing. Later that evening, they have dinner together and continue to discuss their experiences in the neighborhood, and realize 
that they held certain stereotypes about poor people that should be revised. A few days later, they go back to A content at having experienced some of the 'real B'. 9

(III) Poverty Tourism Field Trips. A professor decides to take a group of students from area A to area B. The professor pays an operator in B who provides guides for walking tours of impoverished neighborhoods there. The price of the tour covers the operator's fees and a small donation to a charitable organization working in the neighborhood. On the tour, the operator leads the professor and students through the community, introduces them to community members, gives them opportunities to purchase local food and products, and shows them interesting places. After the tour is over, the professor and students go back to their hotel in a resort district and talk about their experiences around the pool. Several students compare their discussions of poverty at the university with what they found out through personal observation. Many students conclude that they now understand poverty in a different way, and plan to explain their transformation to friends upon their return. They also feel better positioned to make decisions impacting poverty in their future careers.

Examples (I)-(III) may be conducted by themselves or embedded with other types of tourism. Insofar as they can be conducted by themselves, we can see how each can also be mutually beneficial in its own right. Poverty tourism homestays may not leave anyone worse off, and it seems that everyone directly involved receives some accretive benefit. The tourists receive education about poverty. The operators get their fees. The residents get whatever profits accrue from their reimbursements. And charitable organizations receive sponsorship. In side trips, the tourists receive education and the residents may receive some financial compensation if they sold something to the tourists. If all the tourists were just walking around, and if there are no other salient facts regarding the significance of that, then the residents are at least not any worse off. In field trips, similar to homestays, the tourists receive education, the operators get fees, and the residents receive indirect compensation through the charitable organization and economic relations if any purchases were made.

\section{Poverty tourism and exploitation}

Mutually beneficial and Pareto superior cases that meet criteria (1)-(3) cannot be used as indisputable counterexamples because there are good reasons to think that they can involve the kind of wrongful gains characteristic of 'exploitation'. We understand 'exploitation' to be a form of wrongful gain, in accord with other contemporary accounts (Mayer 2007a, 2007b; Meyers 2004; Wertheimer 1996). That is, A gains some benefit wrongfully at the expense of B who is vulnerable in such a way that allows A to get away with it. In some cases, a more serious wrong makes exploitation possible. For example, if a captor exploits hostages for personal gain in the form of ransom, the more serious wrongs are the coercion and degradation required to capture and hold people hostage. However, some cases of exploitation do not involve serious wrongs and may actually render the exploited parties better off than they were before or simply leave them unharmed.

Robert Mayer argues that exploitation is a kind of wrongful gain if some of the parties gain less than they deserve or if gaining nothing at all is less than they deserve, the implication being that Pareto efficiency is not sufficient for the moral acceptability of a transaction. He further outlines three different kinds of underserved losses (Mayer 2007a, 2007b). The first case is of free riders who do not inflict explicit harms on the providers of public goods. Free riders could be considered exploitive if they accept the benefits of public goods without paying a fair share of the costs of creating and maintaining these public goods. (But note that some explicitly call on the poor to free ride in appropriate contexts as an antidote to exploitation (Outterson 2004).) The second case is sweatshops. Sweatshop bosses compensate their employees, but 
they do not 'compensate them sufficiently' for their labor. The third case is drug pushers who benefit their buyers by providing them with drugs. However, drug use is not generally considered a genuine benefit; users are relatively worse off than had they not had access to the drugs, and pushers exploit their dependency (Mayer 2007a, 2007b). In each of these cases, there is some way in which the Pareto superior transaction can be judged as a wrongful gain. Can the same be said for some cases of Pareto superior poverty tourism? Poverty tours are complex activities. Because Pareto calculations assume that participants are able to make welfare-enhancing choices, it can be hard to quantify the harms to other members of the community whose interests are not represented, who did not participate or consent to the transaction, and who are offended by the tour. It is also difficult to capture the frameworks or standards that residents may use to assess - from their perspectives - whether an actual benefit to them is exploitative and morally problematic. In some cases of Pareto superior poverty tourism, we claim that there are at least two legitimate standards by which a tour could be seen as exploitative by the residents in a way that should matter to tourists and operators. The first standard is that a tour may be exploitative if residents' general ability to adapt to or benefit from the tourism activities is less than would be the case were they not living in poverty and subject to tourist activities, and it is this lesser ability to adapt that explains why they do not benefit at all, get less than they deserve, or benefit disingenuously. Our expression of this standard suggests quite a few scenarios in which it may be violated depending on which sorts of 'better off' people serve as the appropriate reference group. Our point is that there are likely at least some instances where the residents would be justified in claiming that they have an unfair opportunity to protect their privacy. In some of these cases, the tourists would be sensitive to this standard were they aware that residents hold it. Another standard may be a disadvantageous bargaining position. The poor may also face more barriers when negotiating compensation from a disadvantaged bargaining position. Though the residents' poverty is the primary focus of poverty tourism, no one should have to face penalties or constraints on their privacy that are caused strictly by their being poor.

It is possible to imagine cases of poverty tourism that meet criteria (1)-(3) that are exploitative in one of the ways outlined by Mayer described earlier in this paper and in terms of the standards just described. The first three cases involve violating the standard in terms of privacy, and the last case involves violating the standard as a disadvantaged bargaining position.

(A) 'Objected poverty tourism' occurs when the tour meets criteria (1)-(3) and, during the course of the tour, the tourists are made aware that the tour is objected to by either a reasonably significant portion of the residents or through some communication arising from a legitimate, community-endorsed process or organization. Consider a garbage dump tour in which a significant number of the scavengers tell the tourists directly that they do not like having their pictures taken or being watched; ${ }^{10}$ or imagine a guided tour where a community-based organization posted signage in the tourists' target language indicating their objections to any poverty tourists in their neighborhood. In these cases, the tourists could argue that there is nothing wrong with what they are doing because the residents are not really harmed by being looked at or having their photos taken. Moreover, they could claim that the poor are in no different a position than the rich, who also are exposed to being toured, e.g. Hollywood tours, etc.

(B) In 'nonconsensual poverty tourism', consent could have been negotiated, but was not. Poverty tourism field trips can be examples of this, where an operator guides a group through an impoverished community. The tourists do not know whether the residents have generally consented or even what they think. ${ }^{11}$ They simply trust that the tourism operator uses good and ethical judgment. The benefits accruing to the residents are in the form of purchases or indirect compensation through a charitable organization.

(C) 'Involuntary poverty tourism' applies to situations where a priori consent is impractical, poverty tourism side trips being an instance. In these cases, the tourists simply walk through a 
neighborhood without any advance planning. They do not know any of the local rules and may even be putting themselves at risk in some way. Interaction is casual and opportunistic. Here, obtaining consent is infeasible; it is difficult to imagine a consent procedure fit for such a scenario. If criticized, tourists who go on these tours may counter that 'all we were doing was taking a walk and taking in the sights!'

Though the tourists may be correct that having one's picture taken or being watched is not explicitly harmful, or that merely taking a walk is not bad, room for exploitation still exists. Poor people cannot take the same measures as rich people to protect their privacy if they are concerned about their privacy. In celebrity tourism, tourists may see wealthy peoples' homes, or observe them going out to eat or dancing at a club, or walking the street. But celebrities can afford to protect themselves from tourists watching their family meals and private moments. They can live in gated communities, protected by private security, assume invasion of privacy because they are celebrities, etc. Many middle class people could exercise similar options, where their neighborhoods are being toured. Certainly people who live in tourism districts take such measures when they can afford it. By contrast, in objected tourism, while it may be unreasonable to stop tourists from viewing everything that the residents object to being viewed, there are still certain things that the residents could do to protect some of their requested privacy were they not extremely poor.

(D) 'Consensual poverty tourism', of which homestays are the paradigmatic example, includes some prior consent process among the tourists, operators, and residents, although the tourists have not collaborated meaningfully with the residents in advance. In some homestays, the operators have met repeatedly with the residents to provide information about the tourists and secure agreement about the terms of the stay. The tourists' interests have likely been expressed through the operators and, by the time the tourists arrive, the residents are quite clear as to what they are supposed to do. We can expect in cases like this that should a tourist act differently than expected, the residents would be able to express this problem to the operators.

Despite the existence of a consent procedure, we need to pay careful attention to both the process and the substance of that consent. As previously discussed, in order for tourism to be poverty tourism, authenticity assurances must have been made. In many homestays, the residents have consented to accept some of these assurances, even if they did not make sense to them. A paradigmatic example is where the residents earn less than the tourists could reasonably be expected to give so as to avoid treating the tourists as guests, as is the case in the Transformational Travel referred to earlier and in other experiences of one of the authors. The tourists' assumption is that such minimal compensation does not incline the residents to treat them any differently (i.e. as privileged guests). Here, the residents consent to settle for less owing to the tourists' authenticity assurance.

The residents gain insufficiently because they would not be in the position to gain income were it not for their willingness to consent to earning less, with the risk being that lack of compliance will incline the tourists to visit another community. If the residents were not poor, they may have better access to information about the true value of their services. The tourists and operators are taking advantage of information asymmetries as well as access to streams of tourists.

These four examples provide a glimpse into issues impacting many poverty tourism scenarios. Our point is not that all poverty tourism meeting criteria (1)-(3) is exploitative. Rather, the claim being advanced is that in Pareto superior scenarios where there is no harm or where all parties benefit, exploitative relationships can still be formed. In this sense, poverty tourism risks involving exploitative transactions, and anyone reflecting on whether to go on such a tour should deliberate about whether such a risk is justifiable in his or her particular situation. 


\section{Conclusion: the risk of exploitation, information, and indulgence}

Suppose a tourist is interested in going on one of the tours described in the previous section. How could that individual discern whether a specific tour is exploitative without giving up criterion (2) or especially (3)? Giving up either criterion would indicate that the tour was a collaborative and consensual enterprise. This difference likely would transform the enterprise into 'pro-poor' (see Goodwin 2009) or 'justice tourism' (see Higgins-Desbiolles 2008); as such, the practice would not be subject to the specific exploitative risk that we have discussed.

Part of finding out whether there is high risk of exploitation involves determining what the residents' perspectives are. If reliable access to their perspectives exists, then perhaps one could find out whether the residents believe that they are in an unfair bargaining position owing to their poverty, or desire privacy for parts of their lives that are exposed to tourists. But the controversial kinds of poverty tourism captured by criteria (1)-(3) afford little opportunity to obtain such access. Consequently, tourists risk exploiting their residents.

Beyond the information gap, an additional consideration remains salient: poverty tourism is an 'indulgent activity'. Tourists do not engage in poverty tourism to survive or remain competitive in business. They cannot legitimately claim they must exploit in order to avoid being pushed out of a niche market or remain competitive under a set of entrepreneurial circumstances. The structural exploitation characteristic of some sweatshop operations is dissimilar, at least when the owners claim that they cannot help but exploit the workers or else be priced out of the market. ${ }^{12}$ Whether to go on a poverty tour is the choice of the tourists based on their interests. But if poverty tourism is indulgent in this way, perhaps would-be tourists should opt to do something else, something where the risk of exploitation of the poor is not as high. Without consent, the risk of exploitation combined with the discretionary nature of the tourism indicates that other activities in the service of the poor were morally preferable to poverty tourism.

Some might object that it is only through personal observation that financially privileged people can change their misconceptions about poverty. But the issue here is not whether corrected misconceptions are good. Rather, our question is whether a poverty tourism experience is a necessary condition for correcting misconceptions. People who believe that they must travel far and wide to rid themselves of harmful stereotypes are being indulgent. That is, they are taking great expense and undertaking significant moral risk to obtain personal observations that will counteract beliefs that traditional forms of education might remedy (Whyte 2010).

Another educational issue concerns whether a personal observation of poverty actually yields any substantial knowledge of why people are poor or what conditions they really face - an issue common to most forms of education. It is unlikely that a two hour, or two day, or even 10 month, poverty tour can produce such knowledge for the tourists. For example, short tours may trigger biases in the tourists that color their evaluation of what they are experiencing. One of the authors of this paper has been on poverty tours where a few tourists end up blaming the victims for not being entrepreneurial enough in response to their poverty. Longer tours, such as homestays, may also be inappropriate for providing education because the residents may not disclose very much about their perspectives on their circumstances. There is also no guarantee that the tourists will be exposed to balanced or authoritative information about the causes of poverty. Ultimately, scholars who specialize on the causes of poverty disagree (Cohen 2010), and it is unlikely that poverty tourism provides the sort of experience that could yield any in-depth knowledge about poverty unless very careful and reflective measures are taken, which would likely involve giving up criterion (3).

Taken in combination, these considerations suggest strongly that individuals should consider very carefully whether to go on a poverty tour. To summarize our main points, first, poverty tourism runs the risk of exploitation. Second, poverty tourism that meets criteria (1)-(3) 
renders little opportunity to find out whether the tour is exploitative since tourists do not have reliable access to the perspectives of the residents. Third, if exploitative in some cases, poverty tourism would be of the indulgent kind: tourists are not compelled to exploit the residents because they themselves will be worse-off if they do not.

We conclude that would-be tourists should either participate in another activity that will benefit the residents or press for transformation of criteria (1)-(3). Realistically, however, criteria (1) and (2) will be part of most poverty tours, with (1) not being inherently morally problematic and (2) being hard to change since the tourists are likely inexperienced observers of poverty. Transforming criterion (3) is the most pressing because issues of access to information, quality of education, and the fairness of control over privacy and compensation can be greatly improved through collaborative and consensual processes. A possible solution to explore would be to set up 'fair trade' poverty tours similar to fair trade programs in other areas. The fair trade standards would aim to ensure that certain collaborative procedures are followed and certain levels of compensation and privacy are protected. They would also provide motivation for would-be tourists to pay more for going on a poverty tour, with assurances that a greater share of the funds accrue to the residents themselves.

Fair trade approaches are also worth exploring because they avoid a version of Jim Butcher's criticism of 'ethical tourism' (in relation to mass tourism) that could be applied to our emphasis on the need to pay attention to the risk of exploitation (Butcher 2009). Butcher responds to an emerging literature that seeks to minimize mass tourists' impacts on host communities by suggesting that tourists go on smaller tours (e.g. ecotourism, volunteer tourism) where they can focus on applying ethical conduct toward the hosts. Butcher claims that advocates of ethical tourism ignore the facts that small-scale tourism cannot aspire to the same scale of developmental benefits of mass tourism and many host communities actually embrace mass tourism because of these benefits. Ethical tourism represents a form of Anthony Gidden's 'life politics', where individual lifestyle choices become the locus for political aspirations such as the alleviation of global poverty (Giddens 1994; Novak et al. 1998). Life politics can lead to tourists' hyper-reflection on their own conduct to the point where they no longer participate in behavior that benefits anyone else. Rather, they focus on increasing their own individual peace of mind through activities that are not harmful yet do not have significant positive impacts.

The cases of poverty tourism that we have described are very different from the mass tourism that Butcher and advocates of ethical tourism are exploring. Poverty tours often occur at a scale where greater collaboration with the residents could increase the benefits that accrue to them substantially. The purpose of fair trade standards for poverty tourism homestays, for example, would be to increase the benefits to the residents who host the tourists by making more information accessible. We also suggest that, in some cases, tourists should not go on a poverty tour and perhaps do something else insofar as the latter would benefit the community more. It is not simply about ensuring that tourists have the peace of mind to have avoided the risk of exploitation. Fair trade standards should be developed as ways to ensure and frame collaborations that address exploitation and increase benefits.

\section{Notes}

1. These criteria allow our inquiry to focus on a narrow version of poverty tourism as opposed to other kinds of tourism in which poverty tourism is often embedded. For example, 'volunteer tourism' occurs when tourists are drawn to a place to do volunteer work as an explicit purpose; 'pro-poor tourism' occurs when resident regions create tour packages that are structured with the explicit purpose of maximizing development outcomes; 'justice tourism' occurs when victims of an injustice organize tours to educate tourists about their situation and rally support. There are literatures on each of these kinds of tourism, as well as others in which poverty tourism may be embedded. see Fennell (2005), Mowforth 
and Munt (2009), Duffy and Smith (2003), Scheyvens (2002), Higgins-Desbiolles (2008), Goodwin (2009), Callanan and Thomas (2005), Di Chiro (2000) and Higgins-Desbiolles (2005).

2. http://www.beyondborders.net/TransformationalTravel.htm (accessed June 20, 2010).

3. Though some look at the tours in Soweto as poverty tourism, most of the tours are 'township tours', the purpose of which is to learn about the local culture, not especially poverty (Ramachander 2007).

4. Some might question this criterion because cases of poverty tourism exist in which the tours are motivated by diverse and complex intentions. True as this can be, our inquiry is limited to cases where the primary purpose of going on a tour is obtaining first-hand experience of poverty because this focus enables us to ask the fundamental question of whether anything is morally wrong with the activity in its simplest form, irrespective of whether additional motivations exist. Others might request clarification on whether personal observation of poverty refers to direct observation of the particular people or of the region of the city that represents the community, or both, among other possible foci and combinations of foci. Our analysis in this paper is not contingent on clarifying a focus that we have in mind and we welcome thought experiments on the connection between our conclusions and various foci.

5. Of course, by 'taken seriously' we mean in the relevant respects. This does not count somebody's objection to somebody simply walking on the public street and behaving well within the bounds of the law.

6. Many do not negotiate in a meaningful sense, but just operate with some tacit non-interference.

7. Quote cited from Selinger $(2010,151)$.

8. The discussion that follows on the examples of poverty tourism can be looked at in relation to Erik Cohen's typology of tourism, though we leave that possible discussion to another paper. See Cohen (1972, 1979).

9. At the American Association of Law Schools 2010 Annual Meeting in New Orleans, the profession organized exactly this sort of tour of the still-devastated poor areas of New Orleans.

10. In the case of a garbage dump tour in Mazatlan that one of the authors is aware of, it implicitly operates with the permission of the local community. First, the guards at the dump gate waive them through, and then the scavengers and their 'bosses' who purchase recycling do the same.

11. Tourists may not consider how they fit into the perceptions, narratives and plans of residents. In the case of tourism in Native American Tribes and First Nations, see Evans-Pritchard (1989) and Peers (1999).

12. In these cases, sweatshops may be impermissible, but the justification for this judgment differs from the justification that would be needed if the owners had the discretion to do something else and other motivations guided their involvement in sweatshops.

\section{References}

Achwal, N. 2010. A new brand of poverty tourism. Next Billion, April 6. NextBillion.net. Acumen Fund and World Resources Institute.

Archibold, R.C. 2010. On Los Angeles bus tour, an insider view of gang life. New York Times, January 16. Baran, M. 2008. Poorism: The economics of exploitation. Travel Weekly, May 5.

Butcher, J. 2009. Against 'ethical tourism'. In Philosophical issues in tourism, ed. J. Tribe, 244-61. Toronto: Channel View Publications.

Callanan, N., and S. Thomas. 2005. Volunteer tourism: Deconstructing volunteer activities within a dynamic environment. In Niche tourism: Contemporary issues, trends, and cases, ed. M. Novelli, 183-200. Burlington, MA: Elsevier Butterworth-Heinemann.

Cohen, E. 1972. Towards a sociology of international tourism. Social Research, 39, no. 1: 164-82.

Cohen, E. 1979. Rethinking the sociology of tourism. Annals of Tourism Research 6, no. 1: 18-35.

Cohen, P. 2010. 'Culture of Poverty' makes a comeback. The New York Times, October 17.

Coleman, S., and M. Crang, eds. 2002. Tourism: Between place and performance. New York: Berghahn Books.

Di Chiro, G. 2000. Bearing witness or taking action? Toxic tourism and environmental justice. In Reclaiming the environmental debate: The politics of health in a toxic culture, ed. R. Hofrichter, 275-300. Cambridge, MA: MIT Press.

Duffy, R., and M. Smith. 2003. The ethics of tourism development. New York: Routledge.

Dworkin, A. 1981. Pornography: Men possessing women. London: The Women's Press.

Evans-Pritchard, D. 1989. How 'they' see 'us': Native American images of tourists. Annals of Tourism Research 16, no. 1: 89-105.

Fennell, D. 2005. Tourism ethics. Bristol, UK: Multilingual Matters Limited.

Freire-Medeiros, B. 2009. The favela and its touristic transits. Geoforum 40, no. 4: 580-8. 
Giddens, A. 1994. Beyond left and right: The future of radical politics. Stanford, CA: Stanford University Press.

Goodwin, H. 2009. Reflections on 10 years of pro-poor tourism. Journal of Policy Research in Tourism, Leisure and Events 1, no. 1: 90-4.

Higgins-Desbiolles, F. 2005. Reconciliation tourism: Challenging the constraints of economic rationalism. In Indigenous tourism: The commodification and management of culture, ed. C. Ryan and M. Aicken, 222-45. Amsterdam: Elsevier.

Higgins-Desbiolles, F. 2008. Justice tourism and alternative globalization. Journal of Sustainable Tourism, 16, no. 3. 345-64.

Johnston, A.M. 2006. Is the sacred for sale? Tourism and indigenous peoples. London: Earthscan.

Kirshenblatt-Gimblett, B. 1998. Destination culture: Tourism, museums, and heritage. Berkeley: University of California Press.

Kohn, S. 2008. Poorism? What is inequality coming to? The Huffington Post, March 11.

Lancaster, J. 2007. Next stop, squalor. Smithsonian Magazine, March 1.

Langton, R. 1990. Whose right? Ronald Dworkin, women, and pornographers. Philosophy and Public Affairs 19, no. 4: 311-59.

Langton, R. 1993. Speech acts and unspeakable acts. Philosophy and Public Affairs 22, no. 4: 293-330.

Mackinnon, C. 1987. Feminism unmodified. Cambridge, MA: Harvard University Press.

Mackinnon, C. 1992. Pornography, civil rights and speech. In Pornography: Women, violence and civil liberties, ed. C. Itzin, 456-512. Oxford: Oxford University Press.

Mayer, R. 2007a. Sweatshops, exploitation, and moral responsibility. Journal of Social Philosophy 38, no. 4: $605-19$.

Mayer, R. 2007b. What's wrong with exploitation? Journal of Applied Philosophy 24, no. 2: 137-50.

Meyers, C.D. 2004. Wrongful beneficence: Exploitation and third world sweatshops. Journal of Social Philosophy 35, no. 3: 319-33.

Moroney, R. 2007. 'Poorism' comes to Mumbai. The Wall Street Journal, March 15.

Mowforth, M., and I. Munt. 2009. Tourism and sustainability: Development and new tourism in the third world. London, UK: Routledge.

Novak, M., A. Giddens, J. Lloyd, P. Ormerod, and Institute of Economic Affairs (Great Britain). 1998. Health and welfare unit. Is there a third way? Essays on the changing direction of socialist thought, choice in welfare. London: IEA Health and Welfare Unit.

Outterson, K. 2004. Free trade against free riders?. Pharma Pricing \& Reimbursement 9, no. 9: 254-55.

Peers, L. 1999. 'Playing ourselves': First nations and native American interpreters at living history sites. The Public Historian 21, no. 4: 39-59.

Ramchander, P. 2007. Towards the responsible management of the socio-cultural impact of township tourism. In Tourism and politics: Global frameworks and local realities, ed. P. Burns and M. Novelli, 149-73. Oxford, UK: Elsevier.

Rice, X. 2009. Kenya's slums attract poverty tourism. Guardian.co.uk, September 25.

Rojek, C., and J. Urry. 1997. Touring cultures: Transformations of travel and theory. London: Routledge.

Rolfes, M. 2010. Poverty tourism: Theoretical reflections and empirical findings regarding an extraordinary form of tourism. GeoJournal 75, no. 5: 421-42.

Scheyvens, R. 2002. Tourism for development: Empowering communities. Harlow, UK: Prentice-Hall.

Selinger, E. 2009. Ethics and poverty tours. Philosophy and Public Policy Quarterly 29, no. 1/2: 2-7.

Selinger, E. 2010. Ethics and poverty tours. In Culture and civilization, vol. 2, ed. Irving Louis Horowitz, 147-65. Piscataway, NJ: Transaction Publishers.

Selinger, E., and K. Outterson. 2010. The ethics of poverty tourism. Environmental Philosophy 7, no. 2: 93-114.

Smith, V. 1989. Hosts and guests: The anthropology of tourism. Philadelphia: University of Pennsylvania Press.

Stalker, I. 2008. 'Poorism' is it a poor excuse to travel? Canadian Travel Press 40, no. 32: 21.

Sturken, M. 2007. Tourists of history: Memory, kitsch, and consumerism from Oklahoma City to ground zero. Durham, NC: Duke University Press.

Weiner, E. 2008. Slum visits: Tourism or voyeurism. New York Times, March 9.

Wertheimer, A. 1996. Exploitation. Princeton, NJ: Princeton University Press.

Whyte, K.P. 2010. An environmental justice framework for indigenous tourism. Environmental Philosophy 7, no. 2: 75-92. 